\title{
Is it Time for Single-Pill Combinations in Dyslipidemia?
}

\author{
François Schiele ${ }^{1,2} \mathbb{D}^{-} \cdot$ Leopoldo Pérez de Isla $^{3,4} \cdot$ Marcello Arca $^{5} \cdot$ Charalambos Vlachopoulos $^{6}$
}

Accepted: 11 August 2021 / Published online: 22 September 2021

(c) The Author(s) 2021

\begin{abstract}
Despite the availability of lipid-lowering therapies (LLTs) that are safe and effective, the overall rate of low-density lipoprotein cholesterol (LDL-C) control at a population level in real-life studies is low. Higher-intensity treatment, earlier intervention, and longer-term treatment have all been shown to improve outcomes. However, in clinical practice, actual exposure to LLT is a product of the duration and intensity of, and adherence to, the treatment. To increase exposure to LLTs, the European Society of Cardiology guidelines recommended a stepwise optimization of LLTs by increasing statin intensity to the maximally tolerated dose, with subsequent addition of ezetimibe and proprotein convertase subtilisin/kexin type 9 (PCSK9) inhibitors. Evidence from randomized controlled trials performed in a range of patients suggested that adding ezetimibe to statins rather than doubling the statin dose resulted in significantly more patients at LDL-C goal and significantly fewer patients discontinuing treatment because of adverse events. In addition, data showed that combination treatments effectively increased exposure to LLT. Despite these data and recommendations, optimization of LLT is often limited to increasing statin dose. Therapeutic inertia and poor treatment adherence are significant and prevalent barriers to increasing treatment exposure. They are known to be influenced by pill burden and complexity of treatment. Single-pill combinations provide a strategic approach that supports the intensification of treatment without increasing pill burden or treatment complexity. Single-pill combinations, compared with free associations, have been shown to increase the adherence to LLT and the percentage of patients at LDL-C goal.
\end{abstract}

François Schiele

francois.schiele@univ-fcomte.fr

1 Department of Cardiology, University Hospital Besancon, 25000 Besancon, France

2 EA3920, University of Franche-Comté, 25000 Besancon, France

3 Servicio de Cardiología, Hospital Clínico San Carlos, Madrid, Spain

4 Facultad de Medicina, Universidad Complutense de Madrid, Madrid, Spain

5 Department of Translational and Precision Medicine, Sapienza University of Rome, Rome, Italy

6 First Department of Cardiology, Hippokration Hospital, Medical School, National and Kapodistrian University of Athens, Athens, Greece

\section{Key Points}

Single-pill combinations provide a strategic approach that supports the intensification of lipid-lowering therapy (LLT) without increasing pill burden or treatment complexity.

Single-pill combinations, compared with free associations, have been shown to increase the adherence to LLT and the proportion of patients at LDL-C goal.

\section{Introduction}

Apolipoprotein-B containing lipids are known to play a fundamental role in the development of atherosclerotic cardiovascular disease (ASCVD). Several hundred epidemiological studies and multiple meta-analyses have reported a log-linear association between level of low-density lipoprotein cholesterol (LDL-C) and risk of 
ASCVD development [1, 2]. In addition, evidence derived from Mendelian randomization observations, epidemiological studies, and clinical intervention trials has shown that aggressive therapeutic targets are needed, mainly in high-risk individuals [1-3]. Lowering plasma LDL-C with lipid-lowering therapies (LLTs; defined herein as statins, ezetimibe, and proprotein convertase subtilisin/kexin type 9 [PCSK9] inhibitors) is associated with a decrease in atheroma progression and major vascular events [4-8], and patients who have low lifetime LDL exposure based on their genetics have a significantly lower risk of having a major coronary event than patients with higher lifetime exposures [9].

Higher-intensity treatment, earlier intervention, and longer-term treatment have all been shown to improve outcomes $[6,10]$. These observations are likely to reflect increases in exposure to LLT and therefore decreases in exposure to LDL-C. In clinical practice, the actual exposure to LLT is a product of intensity and adherence [11]. Overall exposure to LLT is, thus, the product of adherence $\times$ intensity $\times$ treatment duration $[11,12]$.

Despite this understanding that appropriate exposure to LLT reduces lipid levels, atherosclerosis, and cardiovascular risk, control of lipid levels in patients with dyslipidemia remains suboptimal at a population level, and new strategies need to be implemented to improve exposure to LLT [13-16]. The recent cross-sectional EUROASPIRE-V survey (see Table 1 for the full names of trials referred to in this article) from 2016 to $2017(N=7824)$ showed that the LDL-C target level of $<1.8 \mathrm{mmol} / \mathrm{L}(70 \mathrm{mg} / \mathrm{dL})$ was reached by only $30 \%$ of patients with coronary heart disease [13]. Similar observations were made in other highrisk populations, such as patients with heterozygous familial hypercholesterolemia. In the SAFEHEART study $(N=$ $1939),<20 \%$ of patients were at LDL-C target after 5-7 years of follow-up [17]. These control rates would have been even lower if the new LDL-C target of $1.4 \mathrm{mmol} / \mathrm{L}(<55$ $\mathrm{mg} / \mathrm{dL}$ ) had been considered [16].

In this narrative review, we describe the potential benefits of combination treatment. We highlight some of the barriers to lipid control and present data that support the use of single-pill combinations (SPCs) as an approach to increasing exposure to LLT.

\section{Combination Treatments: Evidence Supporting Statin and Ezetimibe Combination}

To increase exposure to LLT, European guidelines recommended add-on treatment with ezetimibe for patients who do not meet their treatment goals on the maximally tolerated dose of statin [18]. Triple therapy with a PCSK9 inhibitor such as evolocumab or alirocumab can be considered for patients who have not met LDL-C targets with ezetimibe/ statin therapy $[18,19]$. However, it is important to note that recent studies showed that a majority of patients are expected to meet LDL-C targets with ezetimibe/statin combinations. According to models, up to $85 \%$ of patients postacute coronary syndrome (ACS) and $81 \%$ of patients with dyslipidemia or coronary artery disease would be unlikely to meet the most recent criteria for triple therapy with a PCSK9 inhibitor; therefore, the focus should remain on combinations of ezetimibe and statins [18, 20, 21].

\subsection{Lipid Levels}

Evidence from randomized controlled trials (RCTs) performed in a range of patients supports the addition of ezetimibe to statins when treatment targets have not been reached [22]. In IMPROVE-IT $(N=18,144)$ [23], in which post-ACS subjects were treated with ezetimibe $10 \mathrm{mg} /$

Table 1 Full names of cited trials

\begin{tabular}{|c|c|}
\hline Study acronym & Full trial name \\
\hline ACTE & $\begin{array}{l}\text { Efficacy and safety of ezetimibe added on to rosuvastatin versus up titration of rosuvastatin in hypercholesterolemic patients at } \\
\text { risk for coronary heart disease }\end{array}$ \\
\hline EUROASPIRE & European action on secondary and primary prevention by intervention to reduce events \\
\hline EXPLORER & Examination of potential lipid-modifying effects of rosuvastatin in combination with ezetimibe versus rosuvastatin alone \\
\hline GRAVITY & Gauging the lipid effects of rosuvastatin plus ezetimibe versus simvastatin plus ezetimibe therapy \\
\hline IMPROVE-IT & Improved reduction of outcomes: vytorin efficacy international trial \\
\hline I-ROSETTE & Ildong rosuvastatin and ezetimibe for hypercholesterolemia \\
\hline PACE & $\begin{array}{l}\text { A randomized, double-blind, active-controlled, multicenter study of patients with primary hypercholesterolemia and high } \\
\text { cardiovascular risk who are not adequately controlled with atorvastatin } 10 \mathrm{mg} \text { : a comparison of the efficacy and safety of } \\
\text { switching to coadministration ezetimibe and atorvastatin versus doubling the dose of atorvastatin or switching to rosuvasta- } \\
\text { tin }\end{array}$ \\
\hline
\end{tabular}

PRECISE-IVUS Plaque regression with cholesterol absorption inhibitor or synthesis inhibitor evaluated by intravascular ultrasound study SAFEHEART Spanish familial hypercholesterolemia cohort 
simvastatin $40 \mathrm{mg}$ or with placebo/simvastatin $40 \mathrm{mg}$ for 6 years, levels of LDL-C were $20 \%$ lower in the ezetimibe/ simvastatin group than in the placebo/simvastatin group (median time-weighted average of $1.4 \mathrm{mmol} / \mathrm{L}[53.7 \mathrm{mg} /$ dL] vs. $1.8 \mathrm{mmol} / \mathrm{L}[69.5 \mathrm{mg} / \mathrm{dL}]$, respectively; $p<0.001$ ). Similarly, data from multiple large RCTs showed that the addition of ezetimibe to statins significantly increased the number of patients at treatment goal (Table 2) [22, $24,25]$. In addition, in multiple trials and meta-analyses, adding ezetimibe to statins rather than doubling the statin dose resulted in significantly more patients at LDL-C goal [25-28]. Pooled data from the ACTE study $(N=440)$ in patients at moderately high/high risk of coronary heart disease showed that the addition of ezetimibe to rosuvastatin 5 or $10 \mathrm{mg}$ reduced LDL-C by $21 \%$, whereas doubling the rosuvastatin dose from 10 to $20 \mathrm{mg}$ reduced LDL-C by $5.7 \%$ (between-group difference 15.2\%; $p<0.001$ ) [28].

The efficacy benefits of adding ezetimibe to a statin treatment appear to be maintained in real-world situations. Analysis of 2004-2008 health records of 11,417 patients with high-risk cardiovascular disease who had not experienced LDL-C control on statin monotherapy showed that switching to combination ezetimibe/simvastatin therapy increased the odds of LDL-C control compared with intensifying statin monotherapy (odds ratio [OR] 2.5; 95\% confidence interval [CI] 2.2-2.9 for LDL-C $<2.6 \mathrm{mmol} / \mathrm{L}[100 \mathrm{mg} / \mathrm{dL}]$ and OR $3.9 ; 95 \%$ CI $3.3-4.5$ for LDL-C $<1.8 \mathrm{mmol} / \mathrm{L}[70 \mathrm{mg} / \mathrm{dL}]$ ) (Fig. 1) [29].

\subsection{Atherosclerosis}

These results are further substantiated by studies showing that combination treatment had a greater effect on atherosclerotic plaque regression than monotherapy with a statin $[8,30,31]$. In a prospective randomized open-label study of patients with stable coronary artery disease needing percutaneous coronary intervention $(\mathrm{N}=51)$, the percent change in plaque volume after 6 months of treatment was significantly greater in the combination ezetimibe $10 \mathrm{mg} /$ rosuvastatin $5 \mathrm{mg}$ group than in the rosuvastatin $5 \mathrm{mg}$ monotherapy

Table 2 Evidence from selected randomized controlled trials supporting the use of add-on ezetimibe to reach LDL-C targets [22, 24-26]

\begin{tabular}{|c|c|c|c|c|c|c|c|}
\hline Study name & $N$ & Patients & Intervention & Control & $\begin{array}{l}\text { Duration } \\
\text { (weeks) }\end{array}$ & $\begin{array}{l}\text { LDL-C goal < } 2.6 \\
\mathrm{mmol} / \mathrm{L}(100 \mathrm{mg} / \\
\mathrm{dL}) ; \text { intervention } \\
\text { vs. control }\end{array}$ & $\begin{array}{l}\text { LDL-C goal of }<1.8 \\
\mathrm{mmol} / \mathrm{L}(70 \mathrm{mg} / \\
\mathrm{dL}) ; \text { intervention vs. } \\
\text { control }\end{array}$ \\
\hline \multicolumn{8}{|c|}{ Strategy: adding ezetimibe vs. maintaining monotherapy dose } \\
\hline EXPLORER [22] & 469 & $\begin{array}{l}\text { Hypercholester- } \\
\text { olemia + high } \\
\text { risk of CHD }\end{array}$ & $\begin{array}{l}\text { Ezetimibe/rosuvas- } \\
\text { tatin } 10 / 40 \mathrm{mg}\end{array}$ & $\begin{array}{l}\text { Rosuvastatin } 40 \\
\text { mg }\end{array}$ & 6 & $\begin{array}{l}94.0 \text { vs. } 79.1 \% \\
\quad p<0.001\end{array}$ & NA \\
\hline EXPLORER [22] & 393 & $\begin{array}{l}\text { Hypercholester- } \\
\text { olemia + very } \\
\text { high risk of CHD }\end{array}$ & $\begin{array}{l}\text { Ezetimibe/rosuvas- } \\
\text { tatin } 10 / 40 \mathrm{mg}\end{array}$ & $\begin{array}{l}\text { Rosuvastatin } 40 \\
\text { mg }\end{array}$ & 6 & NA & $\begin{array}{c}79.6 \text { vs. } 35.0 \% \\
p<0.001\end{array}$ \\
\hline I-ROSETTE [24] & 325 & $\begin{array}{l}\text { Hypercholester- } \\
\text { olemia + CHD/ } \\
\text { CHD risk equiva- } \\
\text { lents }\end{array}$ & $\begin{array}{l}\text { Ezetimibe/rosuvas- } \\
\text { tatin } 10 / 5,10 / 10, \\
\text { or } 10 / 20 \mathrm{mg}\end{array}$ & $\begin{array}{l}\text { Rosuvastatin } 5,10 \text {, } \\
\text { or } 20 \mathrm{mg}\end{array}$ & 8 & $\begin{array}{l}92.0 \text { vs. } 77.8 \% \\
\quad p<0.001\end{array}$ & NA \\
\hline Ran et al. [25] & 84 & $\begin{array}{l}\text { Non-ST-elevation } \\
\text { ACS }\end{array}$ & $\begin{array}{l}\text { Ezetimibe/ rosuvas- } \\
\text { tatin } 10 / 10 \mathrm{mg}\end{array}$ & $\begin{array}{l}\text { Rosuvastatin } 10 \\
\text { mg }\end{array}$ & 6 & NA & $\begin{array}{l}81.0 \text { vs. } 33.3 \% \\
p<0.05\end{array}$ \\
\hline \multicolumn{8}{|c|}{ Strategy: adding ezetimibe vs. doubling monotherapy dose } \\
\hline ACTE [28] & 440 & $\begin{array}{l}\text { Hypercholes- } \\
\text { terolemia }+ \\
\text { moderate-high } \\
\text { CHD risk }\end{array}$ & $\begin{array}{l}\text { Ezetimibe/ rosu- } \\
\text { vastatin } 10 / 5 \text { or } \\
10 / 10 \mathrm{mg}\end{array}$ & $\begin{array}{l}\text { Rosuvastatin } 20 \\
\text { mg }\end{array}$ & 6 & $\begin{array}{l}59.4 \text { vs. } 30.9 \% \\
\quad p<0.001\end{array}$ & $\begin{array}{l}43.8 \text { vs. } 17.5 \% \\
\quad p<0.001\end{array}$ \\
\hline $\begin{array}{r}\text { PACE [26] } \\
\text { (period I) }\end{array}$ & 603 & $\begin{array}{l}\text { Hypercholester- } \\
\text { olemia + high } \\
\text { ASCVD risk }\end{array}$ & $\begin{array}{l}\text { Ezetimibe/atorvas- } \\
\text { tatin } 10 / 10 \mathrm{mg}\end{array}$ & Atorvastatin $20 \mathrm{mg}$ & 6 & $\begin{array}{l}56.3 \text { vs. } 37.4 \% \\
\quad p<0.01\end{array}$ & $\begin{array}{c}19.3 \text { vs. } 3.0 \% \\
p<0.01\end{array}$ \\
\hline $\begin{array}{l}\text { PACE [26] } \\
\text { (period II) }\end{array}$ & 250 & $\begin{array}{l}\text { Uncontrolled on } \\
\text { atorvastatin } 20 \\
\text { mg during phase } \\
1\end{array}$ & $\begin{array}{l}\text { Ezetimibe/atorvas- } \\
\text { tatin } 10 / 20 \mathrm{mg}\end{array}$ & Atorvastatin $40 \mathrm{mg}$ & 6 & $\begin{array}{l}55.8 \text { vs. } 34.1 \% \\
\quad p<0.01\end{array}$ & $\begin{array}{c}18.3 \text { vs. } 0.8 \% \\
p<0.01\end{array}$ \\
\hline Ran et al. [25] & 83 & $\begin{array}{l}\text { Non-ST-elevation } \\
\text { ACS }\end{array}$ & $\begin{array}{l}\text { Ezetimibe/rosuvas- } \\
\text { tatin } 10 / 10 \mathrm{mg}\end{array}$ & $\begin{array}{l}\text { Rosuvastatin } 20 \\
\text { mg }\end{array}$ & 6 & NA & $\begin{array}{l}81.0 \text { vs. } 68.3 \% \\
p<0.05\end{array}$ \\
\hline
\end{tabular}

$A C S$ acute coronary syndrome, $A S C V D$ atherosclerotic cardiovascular disease, $C H D$ coronary heart disease, $L D L$ - $C$ low-density lipoprotein cholesterol, NA not available 


\author{
LDL-C $<100 \mathrm{mg} / \mathrm{dL}$ \\ Switchers vs titrators \\ Switchers vs non-titrators \\ Titra tors vs non-titrators \\ LDL-C $<70 \mathrm{mg} / \mathrm{dL}$ \\ Switchers vs titrators \\ Switchers vs non-titrators \\ Titrators vs non-titrators
}

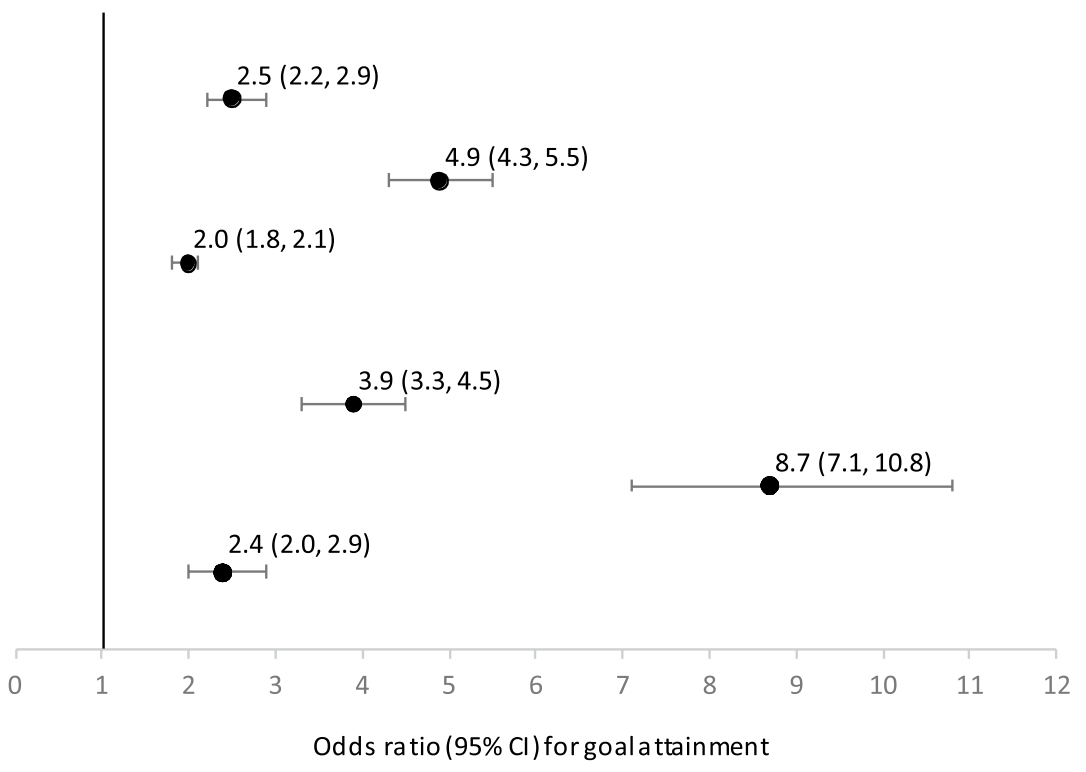

Fig. 1 Efficacy benefits of adding ezetimibe to a statin treatment in real-world situations [29]. Adjusted odds ratios (95\% confidence interval) for the attainment of LDL-C goals among 11,417 patients. Switchers were defined as patients who switched from statin monotherapy to combination ezetimibe/simvastatin $(10 / 10,10 / 20,10 / 40$,

group ( -13.2 vs. $-3.1 \%$, respectively; $p=0.050$ ) [31]. In addition, in the randomized controlled PRECISE-IVUS study $(N=202)$, the combination of ezetimibe/atorvastatin had a significantly greater effect on absolute changes in atheroma volume than did statin monotherapy (median - 3.9 [interquartile range $\{\mathrm{IQR}\}-10.6-0.0] \mathrm{mm}^{3}$ vs. $-1.0[\mathrm{IQR}$ $-6.8-5.7$ ] $\mathrm{mm}^{3} ; p=0.001$ ) [8]. More patients treated with ezetimibe/atorvastatin showed coronary plaque regression (78 vs. $58 \%$ on monotherapy; $p=0.004$ ) [8]. Consistent with these data, a meta-analysis of six studies that used intravascular ultrasound to assess atheroma volume $(N=583)$ showed that treatment with an ezetimibe/statin combination was more effective in reducing total atheroma volume than treatment with a statin in monotherapy (weighted mean difference $-3.71 \mathrm{~mm}^{3}$; $95 \% \mathrm{CI}-5.98$ to $-1.44 ; p<0.001$ ) [30]. Even though it has been claimed that the inhibition of plaque progression may be partially related to the antiinflammatory effects of statins [32], it has definitely been proven that a greater reduction in LDL-C is associated with greater inhibition of plaque progression, making it reasonable to use the maximal tolerated LDL-C-lowering potential to halt atherosclerosis progression.

\subsection{Clinical Outcomes}

Outcomes studies and meta-analyses further support the benefit of treatment with an ezetimibe/statin combination. In IMPROVE-IT, for instance, the risk of patients
10/80 mg) therapy. Titrators were defined as patients who either titrated their statin monotherapy to a higher dose of the same statin or switched to a higher-potency dose of another statin. $70 \mathrm{mg} / \mathrm{dL}=1.81$ $\mathrm{mmol} / \mathrm{L} ; 100 \mathrm{mg} / \mathrm{dL}=2.59 \mathrm{mmol} / \mathrm{L} . L D L-C$ low-density lipoprotein cholesterol. Adapted with permission from Toth et al [29]

post-ACS reaching the primary composite cardiovascular endpoint after 7 years was lower in the ezetimibe 10 $\mathrm{mg} /$ simvastatin $40 \mathrm{mg}$ group than in the placebo/simvastatin $40 \mathrm{mg}$ group (32.7 vs. $34.7 \%$, respectively; hazard ratio [HR] 0.936 [95\% CI 0.89-0.99]; $p=0.016$ ) [23]. In the subset of patients aged $>75$ years, treatment with ezetimibe/simvastatin $40 \mathrm{mg}$ led to significantly greater decreases in the primary composite outcome than treatment with simvastatin monotherapy alone (HR 0.797 [95\% CI 0.704-0.902]) [23]. When total events were considered (5314 first events and 4231 subsequent events), the incidence of cardiovascular events was significantly lower in the ezetimibe/simvastatin group than in the control group (incidence rate ratio 0.91 [95\% CI 0.85-0.97]; $p=0.007$ ) [33]. Similarly, a meta-analysis by Nussbaumer et al. [34] of data from nine RCTs $(N=19,461)$ showed that ezetimibe/statin combination therapy was associated with a significantly lower risk of reaching the composite cardiovascular endpoint than was statin monotherapy (HR 0.94 [95\% CI 0.89-0.99]; $p=0.016$ ) [34]. The clinical benefit of ezetimibe demonstrated in clinical trials was also shown in observational studies: in a population-based cohort study of 212,110 patients who had an ACS between 2006 and 2010, ezetimibe/statin combination, when compared with statin monotherapy, was associated with a significantly lower risk of being rehospitalized because of ACS (HR 0.64 [95\% CI 0.60-0.69]) and a significantly lower risk of having a revascularization procedure (HR 0.69 [95\% CI 0.63-0.76]) [35]. 


\subsection{Safety and Tolerability}

As increasing statin dose is often limited by tolerability, the addition of ezetimibe offers a treatment strategy that supports intensification of treatment without increasing the risk of statin-related adverse events or discontinuations. Studies showed that adding ezetimibe to existing treatment did not significantly increase the rate of drug-related adverse events $[22,23]$ and that combination treatment with ezetimibe/ statin was associated with lower adverse event rates than increasing statin dose $[25,26]$.

In randomized placebo-controlled trials, such as IMPROVE-IT and EXPLORER $(N=469)$, as well as in meta-analyses of RCTs, combination treatment was welltolerated [22, 23, 34, 36, 37]. The meta-analysis by Nussbaumer et al. [34], for instance, showed that ezetimibe/statin combination therapy, compared with statin monotherapy, did not increase the relative risk (RR) of adverse events (RR 0.98 [95\% CI 0.89-1.07]), serious adverse events (RR 1.09 [95\% CI 0.77-1.55]), or discontinuation because of an adverse event (RR 0.85 [95\% CI 0.51-1.43]) [34]. When specific adverse events were looked at in a systematic review of safety data from 14,471 patients enrolled in 18 RCTs, ezetimibe/statin combination therapy, when compared with statin monotherapy over a period of 6-48 weeks, did not result in significant increases in the risk of myalgia, rhabdomyolysis, or gastrointestinal adverse events; in the risk of creatine kinase or transaminase levels rising; or in discontinuations because of adverse events [36]. Despite the fact that a polymorphism in the Niemann-Pick Cl-Like 1 gene, which mimics the effect of ezetimibe, has been associated with gallstone disease [38], observations in clinical studies did not indicate that ezetimibe influenced the occurrence of gallstones [39]. These observations have also been made in high-risk patients. As shown in the IMPROVE-IT trial, the addition of ezetimibe $10 \mathrm{mg}$ to simvastatin $40 \mathrm{mg}$ in patients aged $>75$ years, who are often more susceptible to adverse events because of frailty and polypharmacy, was not associated with a significant increase in safety issues compared with simvastatin $40 \mathrm{mg}$ monotherapy [37].

Importantly, addition of ezetimibe to an existing dose of statin monotherapy may have tolerability benefits over uptitration of the statin dose $[25,26]$. In the PACE $(N=$ 603) study, fewer patients in the combination ezetimibe 10 $\mathrm{mg} /$ atorvastatin $10 \mathrm{mg}$ group than in the atorvastatin $20 \mathrm{mg}$ monotherapy group experienced adverse events (7.5 vs. $11.9 \%$, respectively) and drug-related adverse events ( 0.8 vs. $3.1 \%$, respectively); no significant differences in prespecified events (increases in alanine aminotransferase, aspartate aminotransferase, gastrointestinal adverse events, and allergic reactions) were noted [26]. Similarly, in a 12-week RCT of patients with non-ST-elevation ACS $(N=125)$, the rate of drug-related adverse events was significantly lower in the ezetimibe $10 \mathrm{mg} /$ rosuvastatin $10 \mathrm{mg}$ group than in the rosuvastatin $20 \mathrm{mg}$ group (4.8 vs. $17.0 \%$, respectively; $p<0.05$ ) [25]. In particular, muscle pain was reported by $2.4 \%$ of those in the combination group and $12.2 \%$ in the monotherapy group $(p<0.05)$ [25].

For the management of patients reporting muscular intolerance to statins, a step-by-step approach is recommended to avoid statin cessation and to determine the maximally tolerated statin intensity $[18,40]$. Then, the combination with ezetimibe may compensate the loss of efficacy due to the reduction in statin intensity. Whether SPC could have an incremental advantage over the separate pills in this situation, e.g., by reducing a potential "nocebo effect" by hiding the statin, is hypothetical and not clearly determined.

\section{Barriers to Low-Density Lipoprotein Cholesterol Control: Clinical Inertia and Poor Treatment Adherence}

Despite the availability of these effective lipid-lowering strategies, actual exposure to LLT in real-life situations is insufficient to reach lipid targets; treatment is not escalated in all patients with uncontrolled lipid levels, and not all patients who are prescribed a combination LLT experience lipid control [41]. Adequate exposure, which is a product of intensity of treatment and adherence to treatment, requires that a number of interlinked modifiable factors, such as therapeutic inertia, medication adherence, and persistence, be addressed.

\subsection{Therapeutic Inertia}

As the current treatment strategies for patients who have not experienced control relies on the progressive intensification of statin treatment, followed by the addition of ezetimibe, and finally the addition of a PCSK9 inhibitor, physician willingness to modify treatment is a significant factor in the likelihood of such patients achieving LDL-C control.

Therapeutic inertia, which is defined as a lack of change in treatment despite target goals not being met, has been noted in a number of studies [15, 29, 42]. For instance, analysis of records from 2004 to 2008 in a US managed care database showed that, among the 11,417 patients not at treatment goal on statin therapy, $31.7 \%$ remained on the same dose of statin monotherapy [29]. Similarly, in a Spanish evaluation of 151 physicians, 1452 patients, and 5092 consultations, therapeutic inertia was observed in $43 \%$ of consultations in which a treatment change was warranted [42]. For high-risk patients, pill burden is a significant influencer of the willingness of physicians to escalate treatment.

Therapeutic inertia has been shown to correlate with negative outcomes. In a case-controlled multivariate analysis 
of data from high-risk patients with hypercholesterolemia who had experienced an ischemic event $(N=470)$, therapeutic inertia at baseline was significantly associated with short-term recurrence of ischemic events (OR 2.18 [95\% CI 1.04-4.51], $p<0.05$ ) [43]. Moreover, in a retrospective database study of patients who had a cardiovascular event between 2004 and $2016(N=28,625)$, less than $25 \%$ of patients had experienced lipid control and only $22 \%$ of patients were taking a high-intensity statin 6 months after the index event [15]. Treatment with low-intensity statins was a significant predictor of cardiovascular event recurrence (HR 1.16 [95\% CI 1.06-1.28]; $p=0.002$ ) [15].

\subsection{Adherence and Persistence}

Adherence and persistence are measures of how well a patient follows the prescribed regimen. For long-term treatments, adherence measures the proportion of prescribed medication taken during a defined period of time; persistence measures whether a treatment is continued over time. As with therapeutic inertia, pill burden is a significant influencer of adherence to and persistence with treatment.

Poor adherence and persistence are prevalent patientrelated factors that influence lipid control and rates of negative outcomes [44-46]. In an analysis of Italian primary care data from 18,423 patients with very high cardiovascular risk who initiated treatment with a statin, ezetimibe, or ezetimibe/simvastatin between 2001 and 2013, 39\% and $45 \%$ of patients were poorly adherent to their LLT (proportion of days covered [PDC] $<80 \%$ ) after 3 and 6 months, respectively [45]. Good adherence, when compared with poor adherence, was associated with significantly higher odds of being at LDL-C target after 3 months (OR 2.26 [95\% CI 1.88-2.73]) and after 6 months (OR 2.76 [95\% CI 2.28-3.33]) [45]. Similarly, in a Swedish study of 54,872 patients who had an acute myocardial infarction between 2010 and 2012, 20.2\% of patients did not adhere to their LLT (defined as a coverage ratio $<50 \%$ ) in the year that followed their myocardial infarction [46]. The mortality rate during the second year post-myocardial infarction was $20.9 \%$ in the low-adherence patients and $5.3 \%$ in the highadherence patients. These data translated into an RR of 1.71 (95\% CI 1.59-1.83) for all-cause mortality and 1.62 (95\% CI $1.50-1.75$ ) for cardiovascular disease-related mortality [46].

\section{Combination Treatment Increases Treatment Exposure}

As exposure to treatment is a measure of treatment intensity and treatment adherence, the combined impact of suboptimal LLT intensity and poor adherence on outcomes can be significant. In a cohort of 29,797 patients treated with statins and ezetimibe and followed for 5 years, each $10 \%$ increase in the LLT intensity $\times$ adherence (PDC $\geq 80 \%$ ) product was associated with a $10 \%$ lower risk (HR $0.90[95 \%$ CI 0.86-0.94]) of reaching the composite cardiovascular event endpoint (cardiovascular death, myocardial infarction, unstable angina, ischemic stroke, heart failure, or revascularization) (Fig. 2) [11]. A similar benefit associated with increasing both LLT intensity and adherence was noted in a nationwide population study of 164,565 patients with previous myocardial infarction. Each increase of $10 \%$ in treatment intensity $\times$ adherence was associated with a $15 \%$ reduction of adjusted risk of major cardiovascular events [12].

\section{Benefits and Potential Drawbacks of Single-Pill Combinations}

Though the drivers of therapeutic inertia and poor adherence to treatment are multifactorial [47], pill burden and complexity of treatment have been shown to influence patient ability and willingness to take long-term medication and, as a result, to fuel the reluctance of physicians to add medications to existing regimens. The strategy consisting in prescribing SPCs rather than free associations of multiple pills offers a way to add ezetimibe to an existing statin treatment without increasing pill burden or treatment complexity. This approach, described in an expert opinion paper by the European Society of Cardiology Working Group on Cardiovascular Pharmacotherapy [44], should have been ideally supported by RCTs. However, it is convincingly supported by studies that confirm the bioequivalence of SPCs and multipill associations of ezetimibe/rosuvastatin and ezetimibe/ simvastatin $[48,49]$ and by the results of observational studies and meta-analyses [50-52]. Further, it is worth noting that there are several RCTs of statin/ezetimibe SPCs versus statin monotherapy or other SPC [24, 53-55].

In a retrospective analysis of healthcare records from 2005 to $2008(N=42,460)$, treatment formulation was a significant predictor of adherence (defined as a PDC $\geq 80 \%$ ). Patients newly prescribed an SPC of ezetimibe/simvastatin, simvastatin/niacin, or lovastatin/niacin treatment were $32 \%$ more likely to be adherent to treatment over a 17 - to 19-month period than patients treated with the equivalent multi-pill association (OR 1.32 [95\% CI 1.27-1.36]; $p$ $<0.0001)$ [50]. Similarly, in a large Italian observational study $(N=256,012)$, SPCs of ezetimibe/statins were associated with significantly higher odds of high adherence (defined as a PDC $>75 \%$ ) than were free associations [51]. In particular, the OR for high adherence was 1.84 (95\% CI 1.72-1.86) for the ezetimibe/simvastatin SPC and 2.47 (95\% CI 2.31-2.65) for the ezetimibe/rosuvastatin SPC.

The impact of formulation on lipid levels was recently described in a German retrospective analysis of 2013-2018 


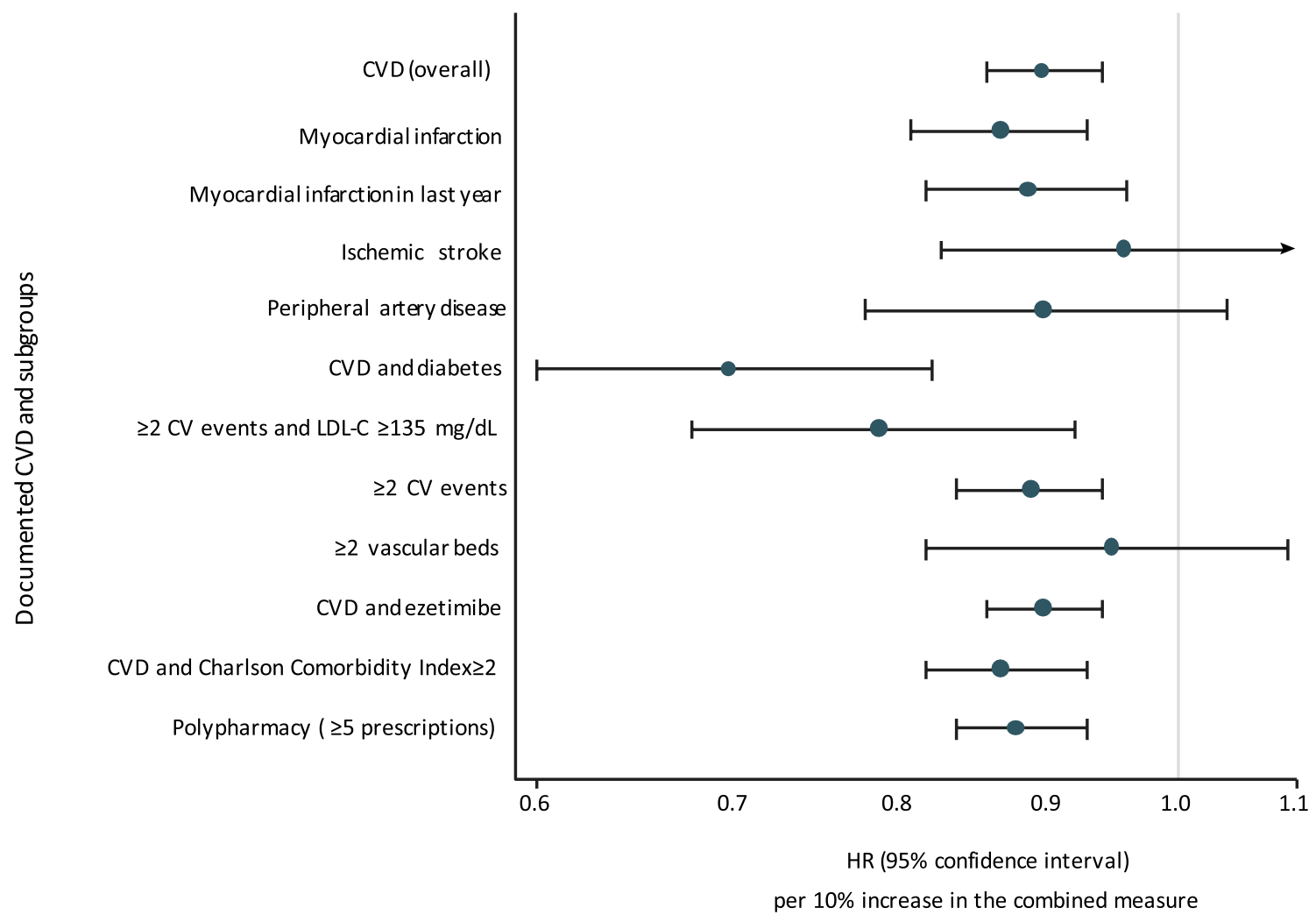

Fig. 2 Decreases in cardiovascular events with each 10\% increase in the combined measure of adherence and treatment intensity in patients treated with statins and/or ezetimibe for 5 years [11]. Cardiovascular events were defined as cardiovascular death, myocardial infarction, unstable angina, ischemic stroke, heart failure, or revascularization. Subgroups are not mutually exclusive. The number of vascular beds ranges from one to three (coronary, cerebrovascular, and peripheral). The model was adjusted for initial use of high-intensity

electronic records of 311,242 patients at high cardiovascular risk. The reduction in LDL-C was larger for patients treated with an SPC of LLTs than for patients treated with a statin and ezetimibe prescribed in a multi-pill association (mean reduction of 28.4 vs. $19.4 \%$, respectively; $p<0.0001$; Fig. 3) [52]. Consequently, a larger proportion of patients were at target LDL-C levels of $<70 \mathrm{mg} / \mathrm{dL}$ ( $31.5 \%$ of SPC treated patients vs. $21.0 \%$ multi-pill association) [52].

Lastly, few studies have been performed to help guide the choice of SPCs. In the GRAVITY trial $(N=833)$, significantly more patients were at LDL-C goal after 6 weeks of SPC treatment with ezetimibe $10 \mathrm{mg} /$ rosuvastatin 20 $\mathrm{mg}$ than with ezetimibe $10 \mathrm{mg} / \mathrm{simvastatin} 40 \mathrm{mg}$ or with ezetimibe $10 \mathrm{mg} /$ simvastatin $80 \mathrm{mg}$, and significantly more patients were at LDL-C goal with ezetimibe $10 \mathrm{mg} / \mathrm{rosu}-$ vastatin $10 \mathrm{mg}$ than with ezetimibe $10 \mathrm{mg} /$ simvastatin 40 mg [56].

Despite similar biological effects and better adherence, potential drawbacks with SPC should also be considered. When side effects are reported by patients, it might be more

therapy, sex, smoking status, hypertension status, antithrombotic medication use, chronic kidney disease status, history of chronic CVD, diabetes status, atrial fibrillation status, year of follow-up, and Charlson Comorbidity Index. $C V$ cardiovascular, $C V D$ cardiovascular disease, $H R$ hazard ratio, $L D L-C$ low-density lipoprotein cholesterol. $135 \mathrm{mg} / \mathrm{dL}=3.49 \mathrm{mmol} / \mathrm{L}$. Adapted with permission from Khunti et al [11]

difficult for the physician to determine the responsibility of the statin or ezetimibe as compared with individual pills. In case of intolerance due to statins (e.g., muscular intolerance), some patients may be tempted to interrupt both statins and ezetimibe, and changes in the dose of statins could be more complex with SPC than with separate treatments.

\section{Additional Examples of Single-Pill Combinations in Cardiovascular Prevention}

While the combination of statins and ezetimibe presents many advantages because of the synergic biologic effect, the demonstrated clinical safety and efficacy, and the affordable cost because of the loss of the patent of both drugs, other types of SPC for cardiovascular prevention may also be of interest in particular patients. Accordingly, the combination of statin + fenofibrate could be considered for patients who need to reduce both LDL-C and triglycerides, or ezetimibe 


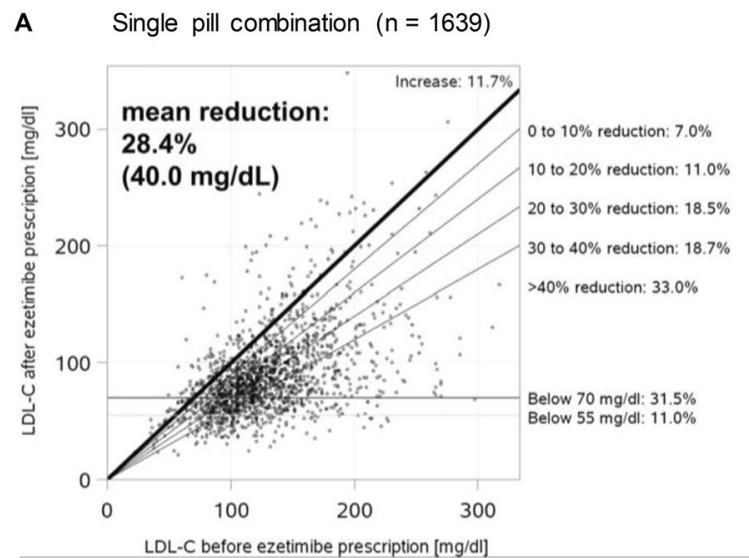

Fig. 3 Efficacy benefits of addition of ezetimibe as a single-pill combination vs. multi-pill association [52]. a Single-pill combination; b multi-pill association. $p<0.0001$ for the difference in LDL-C between groups. Diagonal lines show the percentage of patients with an LDL-C reduction within a specified range. Horizontal lines show

+ bempedoic acid for patients totally intolerant to statins. Other SPCs should be considered to improve adherence for patients who complain about the number of pills, e.g., rosuvastatin + aspirin, rosuvastatin + amlodipine, atorvastatin + perindopril, or a triple association including atorvastatin + amlodipine + perindopril. This strategy is supported by previous data from SPCs for patients with hypertension, for instance.

\section{Conclusions}

Recent European dyslipidemia guidelines recommended add-on treatment with ezetimibe for patients not at treatment goal on the maximally tolerated dose of statin. This combination of statin and ezetimibe reduces LDL-C more effectively, has a greater effect on atherosclerotic plaque regression, and is associated with a significantly lower risk of cardiovascular events than statin monotherapy. Prescribing SPCs rather than free associations of multiple pills offers a way to add ezetimibe to an existing statin treatment to support treatment intensification and the reaching of lipid goals without increasing pill burden or complexity of treatment. This SPC strategy would merit further endorsement by guidelines and better implementation in clinical practice.

Acknowledgements The authors thank Hélène Dassule, $\mathrm{PhD}$ for her medical writing help. Her work was paid for by Servier.

\section{Declarations}

Funding The open access fee for this article was funded by Servier.
B $\quad$ Multi-pill association $(n=796)$

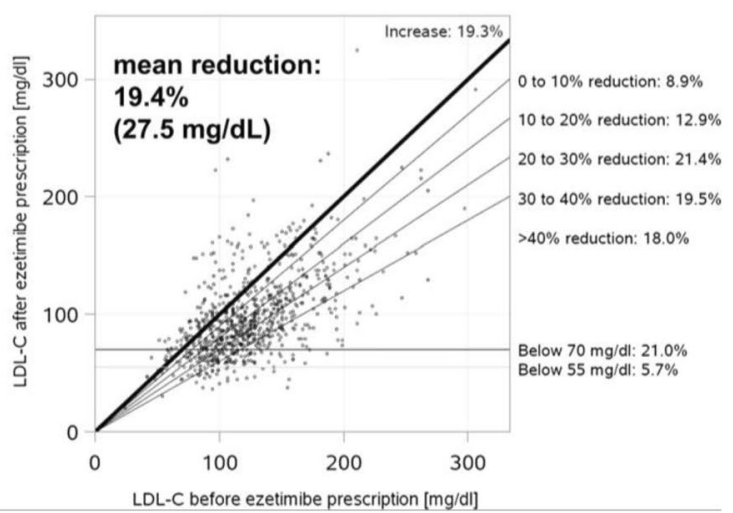

the percentage of patients experiencing LDL-C control defined as $<70 \mathrm{mg} / \mathrm{dL}(1.8 \mathrm{mmol} / \mathrm{L})$ and $<55 \mathrm{mg} / \mathrm{dL}(1.4 \mathrm{mmol} / \mathrm{L})$, respectively. $L D L-C$ low-density lipoprotein cholesterol. Reproduced from Katzmann et al. [52] (published under CC-BY license)

Conflict of interest Francois Schiele has received personal fees from Amgen, Astra Zeneca, Bayer, BMS, MSD, Pfizer, and Sanofi outside the submitted work. Leopoldo Pérez de Isla has received research grants, fees as advisor, and lecturing fees from Servier, Novartis, Amgen, Amryt, Daiichi-Sankyo, Pfizer, Sanofi, Menarini, and Almirall. Marcello Arca has received research grant support and lecturing fees from Amgen, Amryt, IONIS/Akcea Therapeutics, Daiichi-Sankyo, Novartis, Pfizer, Regeneron, and Sanofi. Charalambos Vlachopoulos has received research grant support and lecturing fees from Amgen, Bayer, Boehringer Ingelheim, Mylan, Sanofi, and Servier.

Availability of data and materials Not applicable, as this is a review article.

Ethics approval Not applicable.

Consent Not applicable.

Author contributions All authors made a substantial contribution to the concept or design of the work or acquisition, analysis or interpretation of data. All authors drafted the article or revised it critically for important intellectual content, and approved the version to be published. All authors participated sufficiently in the work to take public responsibility for appropriate portions of the content.

Open Access This article is licensed under a Creative Commons Attribution-NonCommercial 4.0 International License, which permits any non-commercial use, sharing, adaptation, distribution and reproduction in any medium or format, as long as you give appropriate credit to the original author(s) and the source, provide a link to the Creative Commons licence, and indicate if changes were made. The images or other third party material in this article are included in the article's Creative Commons licence, unless indicated otherwise in a credit line to the material. If material is not included in the article's Creative Commons licence and your intended use is not permitted by statutory regulation or exceeds the permitted use, you will need to obtain permission directly from the copyright holder. To view a copy of this licence, visit http://creativecommons.org/licenses/by-nc/4.0/. 


\section{References}

1. Emerging Risk Factors Collaboration, Di Angelantonio E, Sarwar $\mathrm{N}$, et al. Major lipids, apolipoproteins, and risk of vascular disease. JAMA. 2009;302(18):1993-2000. https://doi.org/10.1001/ jama.2009.1619.

2. Sniderman AD, Williams K, Contois JH, et al. A meta-analysis of low-density lipoprotein cholesterol, non-high-density lipoprotein cholesterol, and apolipoprotein B as markers of cardiovascular risk. Circ Cardiovasc Qual Outcomes. 2011;4(3):337-45. https:// doi.org/10.1161/CIRCOUTCOMES.110.959247.

3. Ference BA, Yoo W, Alesh I, et al. Effect of long-term exposure to lower low-density lipoprotein cholesterol beginning early in life on the risk of coronary heart disease: a Mendelian randomization analysis. J Am Coll Cardiol. 2012;60(25):2631-9. https://doi.org/ 10.1016/j.jacc.2012.09.017.

4. Cholesterol Treatment Trialists Collaborators, Mihaylova B, Emberson J, et al. The effects of lowering LDL cholesterol with statin therapy in people at low risk of vascular disease: metaanalysis of individual data from 27 randomised trials. Lancet. 2012;380(9841):581-90. https://doi.org/10.1016/S0140-6736(12) 60367-5.

5. Silverman MG, Ference BA, Im K, et al. Association between lowering LDL-C and cardiovascular risk reduction among different therapeutic interventions: a systematic review and metaanalysis. JAMA. 2016;316(12):1289-97. https://doi.org/10.1001/ jama.2016.13985.

6. Nissen SE, Nicholls SJ, Sipahi I, et al. Effect of very high-intensity statin therapy on regression of coronary atherosclerosis: the ASTEROID trial. JAMA. 2006;295(13):1556-65. https://doi.org/ 10.1001/jama.295.13.jpc60002.

7. Nicholls SJ, Puri R, Anderson T, et al. Effect of evolocumab on progression of coronary disease in statin-treated patients: the GLAGOV randomized clinical trial. JAMA. 2016;316(22):237384. https://doi.org/10.1001/jama.2016.16951.

8. Tsujita K, Sugiyama S, Sumida H, et al. Impact of dual lipidlowering strategy with ezetimibe and atorvastatin on coronary plaque regression in patients with percutaneous coronary intervention: the multicenter randomized controlled PRECISE-IVUS trial. J Am Coll Cardiol. 2015;66(5):495-507. https://doi.org/10. 1016/j.jacc.2015.05.065.

9. Ference BA, Bhatt DL, Catapano AL, et al. Association of genetic variants related to combined exposure to lower low-density lipoproteins and lower systolic blood pressure with lifetime risk of cardiovascular disease. JAMA. 2019; 322(14):1381-1391 https:// doi.org/10.1001/jama.2019.14120.

10. Nissen SE. Effect of intensive lipid lowering on progression of coronary atherosclerosis: evidence for an early benefit from the Reversal of Atherosclerosis with Aggressive Lipid Lowering (REVERSAL) trial. Am J Cardiol. 2005;96(5A):61F-F68. https:// doi.org/10.1016/j.amjcard.2005.07.013.

11. Khunti K, Danese MD, Kutikova L, et al. Association of a combined measure of adherence and treatment intensity with cardiovascular outcomes in patients with atherosclerosis or other cardiovascular risk factors treated with statins and/or ezetimibe. JAMA Netw Open. 2018;1(8): e185554. https://doi.org/10.1001/jaman etworkopen.2018.5554.

12. Schiele F, Quignot N, Khachatryan A, et al. Clinical impact and room for improvement of intensity and adherence to lipid lowering therapy: five years of clinical follow-up from 164,565 postmyocardial infarction patients. Int J Cardiol. 2021; 332:22-28. https://doi.org/10.1016/j.ijcard.2021.03.007.

13. De Backer G, Jankowski P, Kotseva K, et al. Management of dyslipidaemia in patients with coronary heart disease: results from the ESC-EORP EUROASPIRE V survey in 27 countries.
Atherosclerosis. 2019;285:135-46. https://doi.org/10.1016/j. atherosclerosis.2019.03.014.

14. Harris DE, Lacey A, Akbari A, et al. Achievement of European guideline-recommended lipid levels post-percutaneous coronary intervention: a population-level observational cohort study. Eur J Prev Cardiol. 2021; 28(8):854-861 https://doi.org/10.1177/ 2047487320914115.

15. Lassenius MI, Toppila I, Bergius S, Perttila J, Airaksinen KJ, Pietila M. Cardiovascular event rates increase after each recurrence and associate with poor statin adherence. Eur J Prev Cardiol. 2020. https://doi.org/10.1177/2047487320904334.

16. Ray KK, Molemans B, Schoonen WM, et al. EU-wide crosssectional observational study of lipid-modifying therapy use in secondary and primary care: the DA VINCI study. Eur J Prev Cardiol. 2020. https://doi.org/10.1093/eurjpc/zwaa047.

17. Perez de Isla L, Arroyo-Olivares R, Muniz-Grijalvo O, et al. Long-term effect of 2 intensive statin regimens on treatment and incidence of cardiovascular events in familial hypercholesterolemia: the SAFEHEART study. J Clin Lipidol. 2019;13(6):989-96. https://doi.org/10.1016/j.jacl.2019.10.005.

18. Mach F, Baigent C, Catapano AL, et al. 2019 ESC/EAS guidelines for the management of dyslipidaemias: lipid modification to reduce cardiovascular risk. Eur Heart J. 2020;41(1):111-88. https://doi.org/10.1093/eurheartj/ehz455.

19. Grundy SM, Stone NJ, Bailey AL, et al. 2018 AHA/ACC/ AACVPR/AAPA/ABC/ACPM/ADA/AGS/APhA/ASPC/NLA/ PCNA guideline on the management of blood cholesterol: a report of the American College of Cardiology/American Heart Association Task Force on clinical practice guidelines. Circulation. 2019;139(25):e1082-143. https://doi.org/10.1161/CIR. 0000000000000625 .

20. Koskinas KC, Gencer B, Nanchen D, et al. Eligibility for PCSK9 inhibitors based on the 2019 ESC/EAS and 2018 ACC/ AHA guidelines. Eur J Prev Cardiol. 2020. https://doi.org/10. 1177/2047487320940102.

21. Vlachopoulos C, Dima I, Soulis D, et al. Eligibility for PCSK-9 inhibitors treatment in acute coronary syndrome, chronic coronary artery disease and outpatient dyslipidemic patients. Atherosclerosis. 2020;303:29-35. https://doi.org/10.1016/j.ather osclerosis.2020.04.024.

22. Ballantyne CM, Weiss R, Moccetti T, et al. Efficacy and safety of rosuvastatin $40 \mathrm{mg}$ alone or in combination with ezetimibe in patients at high risk of cardiovascular disease (results from the EXPLORER study). Am J Cardiol. 2007;99(5):673-80. https:// doi.org/10.1016/j.amjcard.2006.10.022.

23. Cannon CP, Blazing MA, Giugliano RP, et al. Ezetimibe added to statin therapy after acute coronary syndromes. N Engl J Med. 2015;372(25):2387-97. https://doi.org/10.1056/NEJMoa1410 489.

24. Hong SJ, Jeong HS, Ahn JC, et al. A phase III, multicenter, randomized, double-blind, active comparator clinical trial to compare the efficacy and safety of combination therapy with ezetimibe and rosuvastatin versus rosuvastatin monotherapy in patients with hypercholesterolemia: I-ROSETTE (ildong rosuvastatin and ezetimibe for hypercholesterolemia) randomized controlled trial. Clin Ther. 2018;40(2):226 e4-241 e4. https://doi.org/10.1016/j. clinthera.2017.12.018.

25. Ran D, Nie HJ, Gao YL, et al. A randomized, controlled comparison of different intensive lipid-lowering therapies in Chinese patients with non-ST-elevation acute coronary syndrome (NSTEACS): ezetimibe and rosuvastatin versus high-dose rosuvastatin. Int J Cardiol. 2017;235:49-55. https://doi.org/10.1016/j.ijcard. 2017.02.099.

26. Bays HE, Averna M, Majul C, et al. Efficacy and safety of ezetimibe added to atorvastatin versus atorvastatin uptitration or switching to rosuvastatin in patients with primary 
hypercholesterolemia. Am J Cardiol. 2013;112(12):1885-95. https://doi.org/10.1016/j.amjcard.2013.08.031.

27. Lorenzi M, Ambegaonkar B, Baxter CA, Jansen J, Zoratti MJ, Davies G. Ezetimibe in high-risk, previously treated statin patients: a systematic review and network meta-analysis of lipid efficacy. Clin Res Cardiol. 2019;108(5):487-509. https://doi.org/ 10.1007/s00392-018-1379-Z.

28. Bays HE, Davidson MH, Massaad R, et al. Safety and efficacy of ezetimibe added on to rosuvastatin 5 or $10 \mathrm{mg}$ versus up-titration of rosuvastatin in patients with hypercholesterolemia (the ACTE study). Am J Cardiol. 2011;108(4):523-30. https://doi.org/10. 1016/j.amjcard.2011.03.079.

29. Toth PP, Foody JM, Tomassini JE, et al. Therapeutic practice patterns related to statin potency and ezetimibe/simvastatin combination therapies in lowering LDL-C in patients with high-risk cardiovascular disease. J Clin Lipidol. 2014;8(1):107-16. https:// doi.org/10.1016/j.jacl.2013.09.009.

30. Mirzaee S, Thein PM, Nogic J, Nerlekar N, Nasis A, Brown AJ. The effect of combined ezetimibe and statin therapy versus statin therapy alone on coronary plaque volume assessed by intravascular ultrasound: a systematic review and meta-analysis. J Clin Lipidol. 2018;12(5):1133 e15-1140 e15. https://doi.org/10.1016/j. jacl.2018.06.001.

31. Masuda J, Tanigawa T, Yamada T, et al. Effect of combination therapy of ezetimibe and rosuvastatin on regression of coronary atherosclerosis in patients with coronary artery disease. Int Heart J. 2015;56(3):278-85. https://doi.org/10.1536/ihj.14-311.

32. Diamantis E, Kyriakos G, Quiles-Sanchez LV, Farmaki P, Troupis T. The anti-inflammatory effects of statins on coronary artery disease: an updated review of the literature. Curr Cardiol Rev. 2017;13(3):209-16. https://doi.org/10.2174/1573403X1366617 0426104611 .

33. Murphy SA, Cannon CP, Blazing MA, et al. Reduction in total cardiovascular events with ezetimibe/simvastatin post-acute coronary syndrome: the IMPROVE-IT trial. J Am Coll Cardiol. 2016;67(4):353-61. https://doi.org/10.1016/j.jacc.2015.10.077.

34. Nussbaumer B, Glechner A, Kaminski-Hartenthaler A, Mahlknecht P, Gartlehner G. Ezetimibe-statin combination therapy. Dtsch Arztebl Int. 2016;113(26):445-53. https://doi.org/10.3238/arzte bl.2016.0445.

35. Lin Wu FL, Wang J, Ho W, et al. Effectiveness of a combination of ezetimibe and statins in patients with acute coronary syndrome and multiple comorbidities: a 6-year population-based cohort study. Int J Cardiol. 2017;233:43-51. https://doi.org/10.1016/j. ijcard.2017.02.006.

36. Kashani A, Sallam T, Bheemreddy S, Mann DL, Wang Y, Foody JM. Review of side-effect profile of combination ezetimibe and statin therapy in randomized clinical trials. Am J Cardiol. 2008;101(11):1606-13. https://doi.org/10.1016/j.amjcard.2008. 01.041 .

37. Bach RG, Cannon CP, Giugliano RP, et al. Effect of simvastatin-ezetimibe compared with simvastatin monotherapy after acute coronary syndrome among patients 75 years or older: a secondary analysis of a randomized clinical trial. JAMA Cardiol. 2019;4(9):846-54. https://doi.org/10.1001/jamacardio.2019.2306.

38. Wu J, Cui W, Cai Q, et al. The NPC1L1 polymorphism 1679C >G is associated with gallstone disease in Chinese patients. PLoS ONE. 2016;11(1): e0147562. https://doi.org/10.1371/journal. pone. 0147562

39. Stein A, Hermoni D, Elis A, Konikoff FM. Effect of ezetimibe on the prevalence of cholelithiasis. World J Gastroenterol. 2012;18(40):5789-92. https://doi.org/10.3748/wjg.v18.i40.5789.

40. Toth PP, Patti AM, Giglio RV, et al. Management of statin intolerance in 2018: still more questions than answers. Am J Cardiovasc Drugs. 2018;18(3):157-73. https://doi.org/10.1007/ s40256-017-0259-7.
41. Friedman HS, Rajagopalan S, Barnes JP, Roseman H. Combination therapy with ezetimibe/simvastatin versus statin monotherapy for low-density lipoprotein cholesterol reduction and goal attainment in a real-world clinical setting. Clin Ther. 2011;33(2):212-24. https://doi.org/10.1016/j.clinthera.2011.02. 011.

42. Lazaro P, Murga N, Aguilar D, Hernandez-Presa MA, Investigators IS. Therapeutic inertia in the outpatient management of dyslipidemia in patients with ischemic heart disease. The inertia study. Rev Esp Cardiol. 2010;63(12):1428-37. https://doi.org/10. 1016/s1885-5857(10)70277-2.

43. Diaz Rodriguez A, Murga N, Camafort-Babkowski M, et al. Therapeutic inertia in hypercholesterolaemia is associated with ischaemic events in primary care patients. A case-control study. Int J Clin Pract. 2014;68(8):1001-9. https://doi.org/10.1111/ijcp. 12419.

44. Drexel H, Coats AJS, Spoletini I, et al. An expert opinion paper on statin adherence and implementation of new lipid-lowering medications by the ESC Working Group on cardiovascular pharmacotherapy: barriers to be overcome. Eur Heart J Cardiovasc Pharmacother. 2020;6(2):115-21. https://doi.org/10.1093/ehjcvp/ pvz079.

45. Guglielmi V, Bellia A, Pecchioli S, et al. Effectiveness of adherence to lipid lowering therapy on LDL-cholesterol in patients with very high cardiovascular risk: a real-world evidence study in primary care. Atherosclerosis. 2017;263:36-41. https://doi.org/10. 1016/j.atherosclerosis.2017.05.018.

46. Khalaf K, Johnell K, Austin PC, et al. Low adherence to statin treatment during the first year after an acute myocardial infarction is associated with increased second year mortality riskan inverse probability of treatment weighted study on 54,872 patients. Eur Heart J Cardiovasc Pharmacother. 2021;7(2):141147 https://doi.org/10.1093/ehjcvp/pvaa010.

47. Shawahna R, Odeh M, Jawabreh M. Factors promoting clinical inertia in caring for patients with dyslipidemia: a consensual study among clinicians who provide healthcare to patients with dyslipidemia. J Natl Med Assoc. 2019;111(1):18-27. https://doi.org/10. 1016/j.jnma.2018.04.002.

48. Hwang I, Park SI, Lee S, et al. Pharmacokinetics of fixed-dose combination of rosuvastatin $20 \mathrm{mg}$ and ezetimibe $10 \mathrm{mg}$ compared to concurrent administration of individual tablets in healthy Korean subjects. Transl Clin Pharmacol. 2018;26(1):16-24. https://doi.org/10.12793/tcp.2018.26.1.16.

49. Migoya EM, Bergman A, Hreniuk D, et al. Bioequivalence of an ezetimibe/simvastatin combination tablet and coadministration of ezetimibe and simvastatin as separate tablets in healthy subjects. Int J Clin Pharmacol Ther. 2006;44(2):83-92. https://doi.org/10. 5414/cpp44083.

50. Kamat SA, Bullano MF, Chang CL, Gandhi SK, Cziraky MJ. Adherence to single-pill combination versus multiple-pill combination lipid-modifying therapy among patients with mixed dyslipidemia in a managed care population. Curr Med Res Opin. 2011;27(5):961-8. https://doi.org/10.1185/03007995.2011. 562494.

51. Rea F, Savaré L, Corrao G, Mancia G. Adherence to LipidLowering Treatment by Single-Pill Combination of Statin and Ezetimibe. Adv Ther. 2021. https://doi.org/10.1007/s12325-02101892-7. Epub ahead of print. PMID: 34480293

52. Katzmann JL, Sorio-Vilela F, Dornstauder E, et al. Non-statin lipid-lowering therapy over time in very-high-risk patients: effectiveness of fixed-dose statin/ezetimibe compared to separate pill combination on LDL-C. Clin Res Cardiol. 2020. https://doi.org/ 10.1007/s00392-020-01740-8.

53. Kim KJ, Kim SH, Yoon YW, et al. Effect of fixed-dose combinations of ezetimibe plus rosuvastatin in patients with primary hypercholesterolemia: MRS-ROZE (Multicenter Randomized 
Study of ROsuvastatin and eZEtimibe). Cardiovasc Ther. 2016;34(5):371-82. https://doi.org/10.1111/1755-5922.12213.

54. Yang YJ, Lee SH, Kim BS, et al. Combination therapy of rosuvastatin and ezetimibe in patients with high cardiovascular risk. Clin Ther. 2017;39(1):107-17. https://doi.org/10.1016/j.clinthera. 2016.11.014.

55. Vattimo ACA, Fonseca FAH, Morais DC, et al. Efficacy and tolerability of a fixed-dose combination of rosuvastatin and ezetimibe compared with a fixed-dose combination of simvastatin and ezetimibe in brazilian patients with primary hypercholesterolemia or mixed dyslipidemia: a multicenter, randomized trial. Curr Ther Res Clin Exp. 2020;93: 100595. https://doi.org/10.1016/j.curth eres.2020.100595.

56. Ballantyne CM, Hoogeveen RC, Raya JL, et al. Efficacy, safety and effect on biomarkers related to cholesterol and lipoprotein metabolism of rosuvastatin 10 or $20 \mathrm{mg}$ plus ezetimibe $10 \mathrm{mg}$ vs. simvastatin 40 or $80 \mathrm{mg}$ plus ezetimibe $10 \mathrm{mg}$ in high-risk patients: Results of the GRAVITY randomized study. Atherosclerosis. 2014;232(1):86-93. https://doi.org/10.1016/j.atheroscle rosis.2013.10.022. 